\title{
RNA sequencing on Solanum lycopersicum trichomes identifies transcription factors that activate terpene synthase promoters
}

\author{
Eleni A Spyropoulou, Michel A Haring and Robert C Schuurink ${ }^{*}$
}

\begin{abstract}
Background: Glandular trichomes are production and storage organs of specialized metabolites such as terpenes, which play a role in the plant's defense system. The present study aimed to shed light on the regulation of terpene biosynthesis in Solanum lycopersicum trichomes by identification of transcription factors (TFs) that control the expression of terpene synthases.

Results: A trichome transcriptome database was created with a total of 27,195 contigs that contained 743 annotated TFs. Furthermore a quantitative expression database was obtained of jasmonic acid-treated trichomes. Sixteen candidate TFs were selected for further analysis. One TF of the MYC bHLH class and one of the WRKY class were able to transiently transactivate $S$. Iycopersicum terpene synthase promoters in Nicotiana benthamiana leaves. Strikingly, SIMYC1 was shown to act synergistically with a previously identified zinc finger-like TF, Expression of Terpenoids 1 (SIEOT1) in transactivating the SITPS5 promoter.

Conclusions: High-throughput sequencing of tomato stem trichomes led to the discovery of two transcription factors that activated several terpene synthase promoters. Our results identified new elements of the transcriptional regulation of tomato terpene biosynthesis in trichomes, a largely unexplored field.
\end{abstract}

Keywords: Tomato trichomes, Terpene biosynthesis, Transcription factor, High-throughput sequencing

\section{Background}

Specialized glandular trichomes can produce and accumulate large quantities of terpenoids, phenylpropanoids, flavonoids and alkaloids, which they can also secrete [1]. RNA sequencing in combination with metabolite profile analysis of glandular trichomes and proteomics have shed light on the biosynthesis of specialized metabolites in the trichomes of various plant species [2]. Through the production of EST libraries, micro-arrays and highthroughput sequencing of (glandular) trichome RNA, genes have been identified that are involved in the terpenoid, phenylpropanoid, alkaloid and flavonoid biosynthesis in various plant species, including tomato [3-5], sweet basil [6,7], tobacco [8,9], mint [10], alfalfa [11], Artemisia апnиa [12] and hop [13]. Although EST sequencing has been instrumental in the discovery of enzymes of trichome-

\footnotetext{
* Correspondence: R.C.Schuurink@uva.nl
Department of Plant Physiology, Swammerdam Institute for Life Sciences,

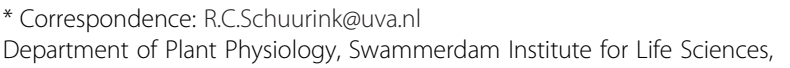
University of Amsterdam, Science Park 904, Amsterdam 1098 XH, The Netherlands
}

specialized metabolism [4], next generation sequencing (NGS) can give a more in-depth picture of transcriptomes. NGS technologies (i.e. RNA sequencing) has been used for characterization of several trichome transcriptomes, for example from plants of medical importance like Artemisia annua (Asteraceae; [12]) or Huperzia serrata and Phlegmariurus carinatus (Huperziaceae; [14]). NGS has also been used for gene discovery, for example in combination with shotgun proteomics and metabolite analysis of tomato (Solanum lycopersicum) trichomes, leading to the discovery of the leaf-trichome-specific $\beta$-caryophyllene/ $\alpha$-humulene synthase (CAHS; [4]). NGS of trichomes RNA from wild and cultivated tomato varieties led to the discovery and characterization of various sesquiterpene synthases, providing insight into the evolution of terpene synthases [15].

Terpene biosynthesis in tomato plants is of major interest because terpenes play an important role in the plant's defense [16-20]. The sequencing of the cultivated tomato genome has enabled the characterization of its terpene synthase (TPS) gene family $[21,22]$, but not much 
is known about the regulation of the terpenoid pathway. Transcriptional control of biosynthetic genes is a major mechanism by which secondary metabolite production is regulated $[23,24]$.

There are not many transcription factors (TFs) known to be involved in regulation of terpenoid pathways. ORCA3, a jasmonate-responsive APETALA2 (AP2)-domain transcription factor from Catharanthus roseus, has been shown to regulate expression of Strictosidine Synthase (STR) involved in terpene indole alkaloid biosynthesis [25]. Subsequently, a methyl-jasmonate (MeJA)-inducible transcription factor of the MYC family $(\mathrm{CrMYC2})$ was shown to positively regulate ORCA3 [26]. CrWRKY1 was identified as being involved in the root-specific accumulation of serpentine in C. roseus plants and as being induced by phytohormones including JA [27]. This TF appeared to negatively regulate ORCA3 and to a lesser extend $\mathrm{CrMYC2}$ [27]. A MeJA-inducible WRKY transcription factor from Gossypium arboreum that regulates the sesquiterpene synthase $(+)-\delta$-cadiene synthase $A$ in cotton fibers was identified by Xu et al. [28]. Ma et al. [29] demonstrated that a MeJA-inducible WRKY transcription factor from Artemisia апnиa is involved in the regulation of artemisinin biosynthesis. More recently two JA-responsive AP2 family transcription factors from $A$. аnnua (AaERF1 and 2) were found to regulate Amorpha-4,11-diene synthase (ADS), a sesquiterpene synthase involved in the biosynthesis of artemisinin [30] whereas Lu et al. [31] identified AaORA, a AP2/ERF TF, that regulates several genes in the artemisinin biosynthetic pathway including AaERF1. Most recently, the MeJA-inducible Arabidopsis thaliana MYC2 transcription factor [32] was shown to regulate sesquiterpene synthases AtTPS21 and AtTPS11 [33].

Here, we used NGS of tomato stem trichomes as a tool for gene discovery. First, a transcript database was created from normalized cDNA, which was mined for transcription factors. Then, in order to narrow down the number of TFs potentially involved in terpene biosynthesis, an expression profiling database was created using Illumina sequencing of trichome RNAs from plants treated with or without jasmonic acid (JA), since JA is known to induce terpene emission in tomato and to regulate several terpene synthases $[16,21,34,35]$. To identify TFs that regulate terpene biosynthesis we used a transient assay based on the transactivation of tomato terpene synthase promoters in planta.

\section{Results}

\section{Assembly of RNAseq data and Genome Analyzer II transcript profiling}

We created a tomato trichome EST database by sequencing a mixture of glandular and non-glandular trichome RNAs, derived from stems of Solanum lycopersicum cv. Moneymaker plants. The resulting cDNA was normalized prior to being used as input for 454 GS FLX Titanium pyrosequencing. A full plate was sequenced consisting of two halves: one with cDNAs originating from control plants and the other half with cDNAs originating from plants treated with JA. In total we obtained 979,076 highquality reads with an average length of $337 \mathrm{bp}$. The reads from control and JA-treated samples were assembled de novo resulting in 27,195 contigs with an average length of $931 \mathrm{bp}$, leaving 24,187 reads unmatched (singletons), with an average length of $241 \mathrm{bp}$. Nucleotide sequences of the contigs were blasted against the Solanaceae Genomics Network (SGN) tomato database for annotation, using a local E-Blast tool; 3,295 contigs were not annotated.

For creating the transcript profiling databases with Genome Analyzer II, the same RNA material as for the 454 sequencing was used, but this time the cDNA derived from control and JA-treated stem trichomes was not normalized before being processed. We specifically obtained 5,631,975 3' sequences from the Control sample and 5,882,547 from the JA-treated sample. 4,840,738 and $5,169,891$ reads from the Control and JA-samples, respectively, were mapped to one unique contig of the trichome database. In addition, 38,699 (C) and 45,375 (JA) reads were mapped to multiple contigs and 791,237 (C) and 712,656 (JA) remained unmapped.

Both the 454. GS FLX Titanium reads and the Genome Analyzer II reads can be found in the Sequence Read Archive of NCBI (http://www.ncbi.nlm.nih.gov/sra) under accession number SRP041373.

\section{Annotation, gene ontology and protein families}

In order to characterize the S. lycopersicum stem trichome transcriptome the unique contigs (27,195 ESTs) were submitted to homology searches (BLASTX) in the National Center for Biotechnology Information (NCBI) non-redundant protein database using Blast2GO [36]. 4,733 contigs did not return a BLASTX hit. The majority of the top hits were to protein sequences of Vitis vinifera, followed by Populus trichocarpa, Ricinus communis and Solanum lycopersicum.

Next, gene ontology (GO) and enzyme classifications (EC) were performed in order to classify the ESTs. It must be noted that one sequence could be assigned to more than one GO term. For the cellular component class the assignments were mostly given to cell and organelle (54,82\% and 29,35\% respectively; Additional file 1: Figure S1a). The highest percentage of molecular function GO terms were in binding and catalytic activity $(42,96 \%$ and 41,38\% respectively; Additional file 1: Figure S1c). In the biological processes, the majority of the GO terms was grouped into two categories- those of metabolic and cellular process $(36,55 \%$ and $32,79 \%$ respectively; Additional file 1: Figure S1b). Finally, within the predicted ECs, the prevailing categories of enzymes were transferases 
and oxidoreductases $(31,38 \%$ and $29,65 \%$ respectively; Additional file 1: Figure S1d).

The search of additional databases for protein families, domains, regions and sites was performed from Blast2GO via the InterPro EBI web server. The 30 top InterPro entries obtained are presented in Table 1 . The most dominant class of enzymes was protein kinases. Abundantly represented were also cytochrome P450s.

Finally, within Blast2GO, the EC numbers were classified in KEGG pathways, enabling the presentation of enzymatic functions in the context of the metabolic pathways in which they are part of (Blast2GO Tutorial, [37]). Among the pathways identified, the ones related to secondary metabolism are shown in Table 2. Lipid transfer proteins represented $0.19 \%$ of the tomato stem trichome transcripts.
Transcripts of enzymes involved in jasmonic acid biosynthesis and signaling pathways were also identified in the trichome database. Data for a selection of enzymes are presented in Table 3, including known JA marker genes such as LOXA (U09026), AOC (AW624058; [38]), JAZ1 (EF591123; [39]) and JAZ3 (EU194561; [40]).

A closer look was taken at the terpene biosynthesis pathway (Figure 1) in order to see if the precursor pathways were up-regulated by JA. As shown in Table 4, expression of some precursor genes in tomato was induced by JA although not strongly (max induction $\sim 2.5$-fold for $H D S$ ). As in other plants [41], genes encoding enzymes of the precursor pathways can belong to small gene families and it appears that expression levels and JA-inducibility of these members can vary. Transcript abundance of precursor genes is presented in Table 4 for comparison with the

Table 1 Summary of the most common InterPro entries found in the S. lycopersicum stem trichome transcriptome

\begin{tabular}{|c|c|c|}
\hline InterPro & Frequency & Description \\
\hline IPR011009 & 571 & Protein kinase-like domain \\
\hline IPR000719 & 521 & Protein kinase, catalytic domain \\
\hline IPR002290 & 336 & Serine/threonine-/dual-specificity protein kinase, catalytic domain \\
\hline IPR008271 & 286 & Serine/threonine-protein kinase, active site \\
\hline IPR020635 & 283 & Tyrosine-protein kinase, catalytic domain \\
\hline IPR016040 & 263 & NAD(P)-binding domain \\
\hline IPR013083 & 239 & Zinc finger, RING/FYVE/PHD-type \\
\hline IPR017441 & 187 & Protein kinase, ATP binding site \\
\hline IPR002885 & 181 & Pentatricopeptide repeat \\
\hline IPR015943 & 175 & WD40/MTN repeat-like-containing domain \\
\hline IPR001841 & 172 & Zinc finger, RING-type \\
\hline IPR012677 & 172 & Nucleotide-binding, alpha-beta plait \\
\hline IPR016024 & 166 & Armadillo-type fold \\
\hline IPR001245 & 164 & Serine-threonine/tyrosine-protein kinase catalytic domain \\
\hline IPR000504 & 158 & RNA recognition motif domain \\
\hline IPR001680 & 153 & WD40 repeat \\
\hline IPR011046 & 152 & WD40 repeat-like-containing domain \\
\hline IPR011990 & 147 & Tetratricopeptide-like helical \\
\hline IPR011989 & 145 & Armadillo-like helical \\
\hline IPR001128 & 141 & Cytochrome P450 \\
\hline IPR017986 & 133 & WD40-repeat-containing domain \\
\hline IPR017853 & 130 & Glycoside hydrolase, superfamily \\
\hline IPR012287 & 119 & Homeodomain-related \\
\hline IPR001611 & 115 & Leucine-rich repeat \\
\hline IPR009057 & 115 & Homeodomain-like \\
\hline IPR016196 & 112 & Major facilitator superfamily domain, general substrate transporter \\
\hline IPR012336 & 108 & Thioredoxin-like fold \\
\hline IPR013781 & 107 & Glycoside hydrolase, subgroup, catalytic domain \\
\hline IPR002213 & 102 & UDP-glucuronosyl/UDP-glucosyltransferase \\
\hline IPR002401 & 95 & Cytochrome P450, E-class, group I \\
\hline
\end{tabular}


Table 2 KEGG pathways related to biosynthesis of secondary metabolites found in the S. lycopersicum stem trichome transcriptome

\begin{tabular}{|c|c|c|c|}
\hline KEGG pathway & EC nr & Enzyme name & $\mathrm{Nr}$ of sequences \\
\hline \multirow[t]{14}{*}{ Terpenoid biosynthesis } & ec:1.1.1.208 & (+)-neomenthol dehydrogenase & 1 \\
\hline & ec:4.1.1.33 & diphosphomevalonate decarboxylase & 3 \\
\hline & ec:2.2.1.7 & 1-deoxy-D-xylulose-5-phosphate synthase & 2 \\
\hline & ec:1.17.1.2 & 4-hydroxy-3-methylbut-2-enyl diphosphate reductase & 1 \\
\hline & ec:2.7.7.60 & 2-C-methyl-D-erythritol 4-phosphate cytidylyltransferase & 1 \\
\hline & ec:2.5.1.1 & dimethylallyltranstransferase & 1 \\
\hline & ec:1:17.7.1 & (E)-4-hydroxy-3-methylbut-2-enyl-diphosphate synthase & 1 \\
\hline & ec:2.7.1.148 & 4-(cytidine 5'-diphospho)-2-C-methyl-D-erythritol kinase & 1 \\
\hline & ec:1.1.1.267 & 1-deoxy-D-xylulose-5-phosphate reductoisomerase & 1 \\
\hline & ec:1.1.1.34 & hydroxymethylglutaryl-CoA reductase (NADPH) & 6 \\
\hline & ec:2.5.1.31 & ditrans,polycis-undecaprenyl-diphosphate synthase & 4 \\
\hline & ec:2.3.3.10 & hydroxymethylglutaryl-CoA synthase & 6 \\
\hline & ec:5.3.3.2 & isopentenyl-diphosphate Delta-isomerase & 2 \\
\hline & ec:2.5.1.32 & phytoene synthase & 2 \\
\hline \multirow[t]{6}{*}{ Phenylpropanoid biosynthesis } & ec:2.1.1.104 & caffeoyl-CoA O-methyltransferase & 4 \\
\hline & ec:1.11.1.7 & peroxidases & 56 \\
\hline & ec:3.2.1.21 & beta-glucosidase & 7 \\
\hline & ec:2.1.1.68 & caffeate O-methyltransferase & 1 \\
\hline & ec:1.14.13.11 & trans-cinnamate 4-monooxygenase & 1 \\
\hline & ec:6.2.1.12 & 4-coumarate—CoA ligase & 4 \\
\hline \multirow[t]{9}{*}{ Flavonoid biosynthesis } & ec:2.1.1.104 & caffeoyl-CoA O-methyltransferase & 4 \\
\hline & ec:2.3.1.74 & naringenin-chalcone synthase & 2 \\
\hline & ec:1.14.11.23 & flavonol synthase & 7 \\
\hline & ec:1.14.13.88 & flavonoid 3',5'-hydroxylase & 3 \\
\hline & ec:1714.11.9 & flavanone 3-dioxygenase & 1 \\
\hline & ec:1.1.1.219 & dihydrokaempferol 4-reductase & 2 \\
\hline & ec:1.14.13.21 & flavonoid 3'-monooxygenase & 3 \\
\hline & ec:1.14.13.11 & trans-cinnamate 4-monooxygenase & 1 \\
\hline & ec:5.5.1.6 & chalcone isomerase & 1 \\
\hline \multirow[t]{4}{*}{ Alkaloid biosynthesis } & ec:4.3.3.2 & strictosidine synthase & 2 \\
\hline & ec:4.1.1.28 & aromatic-L-amino-acid decarboxylase & 4 \\
\hline & ec:1.14.11.20 & deacetoxyvindoline 4-hydroxylase & 1 \\
\hline & ec:2.6.1.42 & branched-chain-amino-acid transaminase & 3 \\
\hline \multirow[t]{8}{*}{ Steroid biosynthesis } & ec:1.14.21.6 & lathosterol oxidase & 1 \\
\hline & ec:2.1.1.41 & sterol 24-C-methyltransferase & 1 \\
\hline & ec:2.5.1.21 & squalene synthase & 2 \\
\hline & ec:5.3.3.5 & cholestenol Delta-isomerase & 1 \\
\hline & ec:2.1.1.6 & catechol O-methyltransferase & 1 \\
\hline & ec:1.1.1.145 & 3beta-hydroxy-Delta5-steroid dehydrogenase & 2 \\
\hline & ec:1.14.14.1 & unspecific monooxygenase & 1 \\
\hline & ec:13.399.5 & 3-oxo-5alpha-steroid 4-dehydrogenase & 4 \\
\hline
\end{tabular}


Table 3 List of selected enzymes involved in the jasmonic acid biosynthesis and signaling

\begin{tabular}{llllllll}
\hline Abbreviation & Contig Nr & SGN Nr & Annotation & $\begin{array}{l}\text { Transcript length } \\
\text { (bases) }\end{array}$ & $\begin{array}{l}\text { Expression } \\
\text { values JA }\end{array}$ & $\begin{array}{l}\text { Expression } \\
\text { values C }\end{array}$ & $\begin{array}{l}\text { Fold JA } \\
\text { induction }\end{array}$ \\
\hline LOXA $^{\text {a }}$ & 6402 & SGN-U592535 & Lipoxygenase A & 2837 & 35.2 & 1.6 & 22 \\
AOC $^{\text {a }}$ & 24817 & SGN-U562649 & Allene oxide cyclase & 1645 & 1898.8 & 417.6 & 4.5 \\
JAZ1 $^{\text {b }}$ & 6863 & SGN-U579837 & Jasmonate ZIM-domain 1 & 1156 & 12.2 & 0.7 & 17.4 \\
JAZ3 $^{\text {c }}$ & 20751 & SGN-U564446 & Jasmonate ZIM-domain 3 & 986 & 18.87 & 2.3 & 8.2 \\
COI1 $^{\text {a }}$ & 24353 & SGN-U568988 & Coronatine-insensitive 1 & 2260 & 11 & 8.5 & 1.29 \\
\hline
\end{tabular}

a[38]: LOXA (U09026), AOC (AW624058), COI1 (NM_001247535), b[39]: JAZ1 (EF591123), c[40]: JAZ3 (EU194561).

*Expression values are in RPKM (reads per kilobase of transcript per million mapped reads).

expression levels of the 13 terpene synthases (TPSs) found in stem trichomes Table 5).

\section{Selection of transcription factors potentially involved in regulating terpene synthases}

Based on the annotated contigs 743 transcription factors of different classes were found in the trichome database: 69 WRKY, 151 MYB, 8 MYC, 52 bZIP, 9 ARF, 71 ERF, $17 \mathrm{ZnF}, 28 \mathrm{bHLH}, 12 \mathrm{MADS}, 1 \mathrm{NAC}$ and 325 of unknown function/class. Out of those, 151 were up-regulated $(>1.5 \mathrm{x})$ by the treatment with JA, 119 were down-regulated $(<0.67 \mathrm{x})$ and expression of $473 \mathrm{TFs}$ remained unaltered. Since JA is known to play a role in the plant's direct and indirect defenses we were interested in those transcription factors that were induced by JA and could therefore potentially be involved in up-regulating terpene biosynthesis. 56 of the TFs that were up-regulated by JA showed an induction higher than 2-fold. The sequence of these 56 TFs was blasted against the tomato genomic sequence (Solanaceae Genomics Network, SGN) and complete ORFs were constructed when possible (GENSCAN, [46]), if not provided by the RNAseq. These sequences were submitted to homology search after translation against the NCBI database for identifying conserved domains. From this analysis 16 TFs (Table 6) were selected for further investigation as follows: we focused on classes of TFs involved in the regulation of terpenoids identified so far in other plant speciesnamely TFs of the APETALA2 class [25,30,31], WRKY class [27-29] and MYC class [26,33]. In total eleven transcription factors of the AP2 class, four of the WRKY class and one of the MYC class, although it only showed a 1.4-fold induction, were selected for further investigation of their potential involvement in regulating expression of terpene synthases.

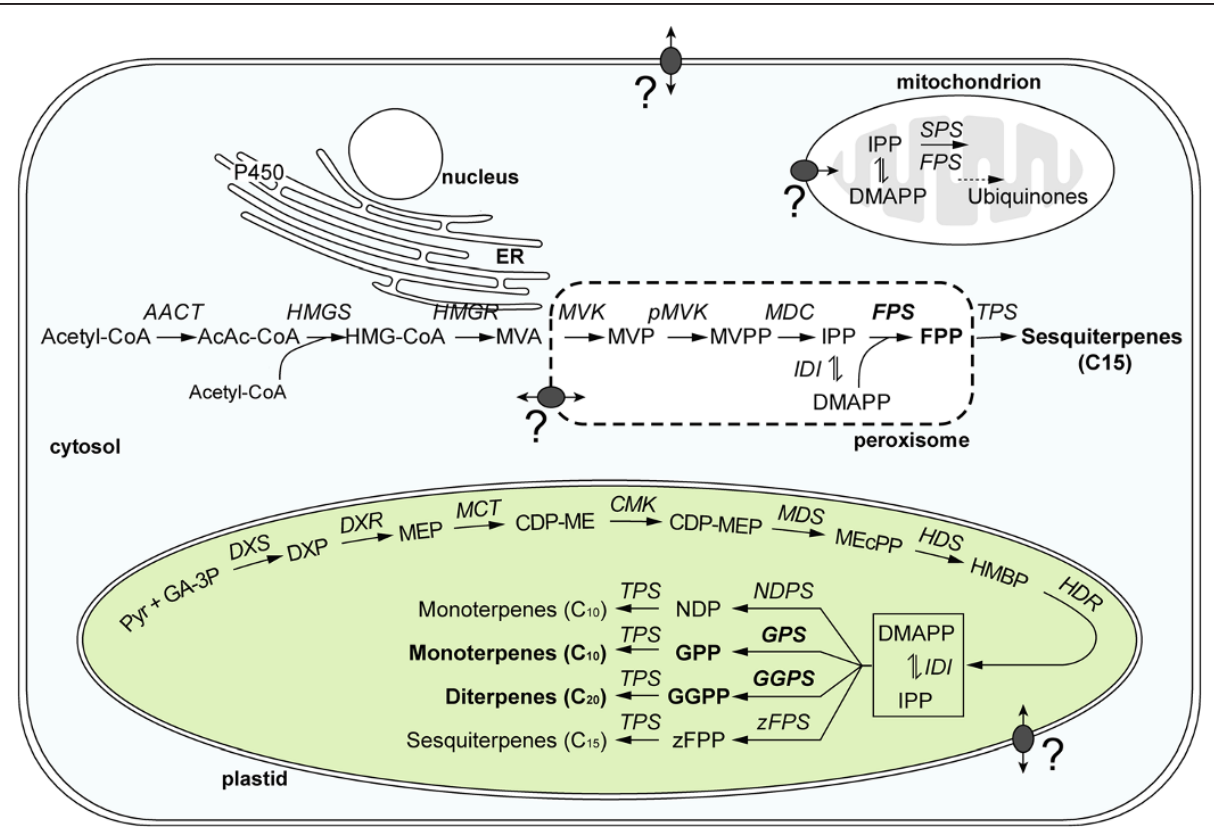

Figure 1 Enzymes involved in the precursor biosynthesis for mono-(C10), sesqui-(C15) and di-(C20) terpenes. An explanation of the abbreviations used in the pathways and the GAll reads for each enzyme are shown in Tables 4 and 5, respectively. ER; endoplasmic reticulum, TPS; terpene synthase, SPS; solanesyl diphosphate synthase. The grey oval circles between organelles and at the cell membrane represent putative transporter systems. Peroxisomal localization of precursor enzymes of the MVA pathway has been previously reported in Arabidopsis thaliana and Catharanthus roseus [42-44]. 
Table 4 Enzymes involved in the biosynthesis of precursors of mono-, sesqui- and diterpenes

\begin{tabular}{|c|c|c|c|c|c|c|}
\hline Abbreviation & Name & Chr & SGN nr & $\begin{array}{l}\text { Expression } \\
\text { values } \mathrm{JA}^{*}\end{array}$ & $\begin{array}{l}\text { Expression } \\
\text { values } C^{*}\end{array}$ & $\begin{array}{l}\text { Fold JA } \\
\text { induction }\end{array}$ \\
\hline \multirow[t]{2}{*}{ AACT } & acetoacetyl-coenzyme A thiolase & 5 & SGN-U566720 & 351.04 & 275.21 & 1.27 \\
\hline & & 7 & SGN-U566719 & 126.3 & 133.52 & 0.94 \\
\hline \multirow[t]{2}{*}{ HMGS } & 3-hydroxy-3-methylglutaryl-CoA synthase & 8 & SGN-U579858 & 14.96 & 15.98 & 0.93 \\
\hline & & 8 & SGN-U578388 & 205.34 & 123.57 & 1.66 \\
\hline \multirow[t]{3}{*}{ HMGR } & 3-hydroxy-3-methylglutaryl-CoA reductase & 2 & SGN-U580675 & 2.2 & 1.06 & 2.07 \\
\hline & & 2 & SGN-U578017 & 19.2 & 22.19 & 0.86 \\
\hline & & 3 & SGN-U579319 & 43.35 & 24.5 & 1.77 \\
\hline MVK & mevalonate kinase & 1 & SGN-U567385 & 198.89 & 125 & 1.59 \\
\hline pMVK & phosphomevalonate kinase & 8 & SGN-U583971 & 46.92 & 54.51 & 0.86 \\
\hline \multirow[t]{2}{*}{ MDC } & mevalonate diphosphate decarboxylase & 4 & SGN-U587221 & 3.4 & 3.19 & 1.06 \\
\hline & & 11 & SGN-U581971 & 26.68 & 35.51 & 0.75 \\
\hline DXS1 & 1-deoxy-D-xylulose 5-phosphate synthase 1 & 1 & SGN-U567647 & 24.14 & 35.33 & 0.68 \\
\hline DXS2 & 1-deoxy-D-xylulose 5-phosphate synthase 2 & 11 & SGN-U582996 & 37.23 & 22.72 & 1.64 \\
\hline DXR & 1-deoxy-D-xylulose 5-phosphate reductoisomerase & 3 & SGN-U585813 & 657.7 & 497.34 & 1.32 \\
\hline MCT & 4-diphosphocytidyl-2-C-methyl-D-erythritol synthase & 1 & SGN-U566797 & 107.95 & 121.45 & 0.89 \\
\hline CMK & 4-diphosphocytidyl-2-C-methyl-D-erythritol kinase & 1 & SGN-U583224 & 275.9 & 237.57 & 1.16 \\
\hline MDS & 2C-methyl-D-erythritol 2,4-cyclodiphosphate synthase & 8 & SGN-U568497 & 36.72 & 41.73 & 0.88 \\
\hline HDS & 1-hydroxy-2-methyl-2-(E)-butenyl 4-diphosphate synthase & 11 & SGN-U567167 & 30.43 & 12.25 & 2.48 \\
\hline HDR & 1-hydroxy-2-methyl-2-(E)-butenyl 4-diphosphate reductase & 1 & SGN-U580658 & 2916.93 & 2720.54 & 1.07 \\
\hline \multirow[t]{2}{*}{$|\mathrm{D}|$} & isopentenyl diphosphate isomerase & 5 & SGN-U569721 & 3.4 & 1.95 & 1.74 \\
\hline & & 4 & SGN-U577516 & 957.4 & 749.11 & 1.28 \\
\hline GPS & geranyl diphosphate synthase & 8 & SGN-U573523 & 2.71 & 3.36 & 0.8 \\
\hline NDPS (CPT1) & neryl diphosphate synthase & 8 & SGN-U583641 & 2810.51 & 4696.4 & 0.6 \\
\hline \multirow[t]{3}{*}{ FPS } & farnesyl diphosphate synthase & 12 & SGN-U580757 & 11.05 & 9.76 & 1.13 \\
\hline & & 10 & SGN-U578686 & 0.68 & 1.24 & 0.55 \\
\hline & & 10 & SGN-U581576 & 15.98 & 25.21 & 0.63 \\
\hline \multirow[t]{3}{*}{ GGPS } & geranyl geranyl diphosphate synthase & 4 & SGN-U571085 & 6.12 & 7.46 & 0.82 \\
\hline & & 9 & SGN-U575882 & 63.58 & 66.05 & 0.96 \\
\hline & & 2 & SGN-U573348 & 17.17 & 34.8 & 0.49 \\
\hline CPT3 & cis-prenyl transferase 3 & 3 & SGN-U572901 & 14.45 & 17.58 & 0.82 \\
\hline CPT4 & cis-prenyl transferase 4 & 10 & SGN-U568982 & 9.52 & 7.28 & 1.3 \\
\hline CPT5 & cis-prenyl transferase 5 & 10 & SGN-U585528 & 120.17 & 70.3 & 1.7 \\
\hline CPT7 & cis-prenyl transferase 7 & 6 & SGN-U574892 & 291.53 & 471.59 & 0.62 \\
\hline
\end{tabular}

Chr; chromosome.

*Expression values are in RPKM (reads per kilobase of transcript per million mapped reads).

For an overview of the biosynthetic pathway see Figure 1.

Tissue specificity and JA responsiveness of selected transcription factors

The sixteen candidate TFs should ideally be trichomespecifically expressed and possibly induced by jasmonic acid. In order to investigate the expression pattern of these genes, cDNA was synthesized from different $S$. lycopersicum cv. Moneymaker organs and tissues: leaves, stems, isolated stem trichomes and roots from 4-week-old plants, as well as flowers and fruit of mature plants. In
Figure 2 transcript levels, as determined by Q-RT-PCR, are presented for four of the sixteen selected transcription factors. For the other twelve candidate TFs expression in the trichomes was much lower than that in the other organs/tissues and these were excluded from further analysis. TF SIMYC1 (KF430611) was predominately expressed in trichomes, but also in leaves and flowers (Figure 2a). SlWRKY78 was expressed in leaves, trichomes, roots and flowers (Figure 2b). SlWRKY28 was a trichome-specific 
Table 5 Terpene synthases (TPS) found in S. lycopersicum stem trichomes

\begin{tabular}{ccccc}
\hline TPS & $\begin{array}{c}\text { Transcript length } \\
\text { (bases) }\end{array}$ & $\begin{array}{c}\text { Expression } \\
\text { values JA }^{*}\end{array}$ & $\begin{array}{c}\text { Expression } \\
\text { values } \mathbf{C}^{*}\end{array}$ & $\begin{array}{c}\text { Fold JA } \\
\text { induction }\end{array}$ \\
\hline 3 & 2099 & 15.8 & 2.3 & 6.87 \\
5 & 2186 & 103.18 & 46.7 & 2.2 \\
7 & 1069 & 0.5 & 0.18 & 2.78 \\
9 & 2011 & 3060.75 & 2359.03 & 1.3 \\
12 & 407 & 4.08 & 2.66 & 1.53 \\
16 & 1868 & 18.36 & 16.87 & 1.09 \\
17 & 1190 & 4.25 & 3.55 & 1.2 \\
19 & 776 & 44.7 & 37.46 & 1.19 \\
20 & 1148 & 142.79 & 106.89 & 1.33 \\
24 & 854 & 0.17 & 0.18 & 0.94 \\
31 & 1991 & 0.68 & 0.18 & 3.78 \\
39 & 1131 & 12.07 & 5.68 & 2.12 \\
41 & 2368 & 71.57 & 66.58 & 1.07 \\
\hline
\end{tabular}

*Expression values are in RPKM (reads per kilobase of transcript per million mapped reads).

For SITPS8 no transcripts were identified in the stem trichome database although by Q-RT-PCR minimal expression has been observed [45]. gene (Figure 2c) and SlWRKY73 was expressed in trichomes, roots and fruit (Figure 2d). Q-RT-PCR analyses indicated that none of the selected transcription factors was significantly induced by JA according (Figure 2). SlWRKY73 expression appeared to be approximately $1.7-$ fold reduced in JA treated plants $(\mathrm{p}=0.07)$.

\section{SIMYC1 and SIWRKY73 can transactivate terpene synthase} promoters in Nicotiana benthamiana leaves

In order to investigate whether these TFs could activate a selection of terpene synthase promoters, a transient assay in Nicotiana benthamiana leaves was used, which has been previously shown to work for the interaction between the zinc finger-like transcription factor Expression of Terpenoids 1 (SIEOT1) and the SITPS5 promoter [47]. In the reporter construct, expression of $\beta$-glucuronidase (uidA, GUS) is driven by the glandular trichomespecific promoter of SITPS5. Co-infiltration with the 35S: SIEOT1 effector construct resulted in transactivation of the SITPS5 promoter, leading to GUS expression in this heterologous system (Figure 3). As negative control for the effector, a 35S:RFP construct was used. Various other reporter constructs with promoters of other terpene synthases- SITPS3, SITPS7 and SITPS8- driving expression of GUS or a GUSsYFP1 fusion (SITPS9) were included in the analyses.

Table 6 List of selected S. lycopersicum transcription factors (TF) potentially involved in terpene biosynthesis

\begin{tabular}{|c|c|c|c|c|c|c|c|}
\hline Name & Contig nr & SGN nr & Annotation & $\begin{array}{l}\text { Transcript } \\
\text { length (bases) }\end{array}$ & $\begin{array}{l}\text { Expression } \\
\text { values } J A^{*}\end{array}$ & $\begin{array}{l}\text { Expression } \\
\text { values } C^{*}\end{array}$ & $\begin{array}{l}\text { Fold JA } \\
\text { induction }\end{array}$ \\
\hline SIAP2_9 & 83 & SGN-U572361 & $\begin{array}{l}\text { ERF (ethylene response factor) subfamily } \\
\text { B-3 of ERF/AP2 TF family }\end{array}$ & 371 & 9.69 & 4.08 & 2.37 \\
\hline SIAP2_2 & 1719 & SGN-U596590 & DREB subfamily A-1 of ERF/AP2 TF family & 422 & 13.6 & 1.95 & 6.97 \\
\hline SIAP2_6 & 5289 & SGN-U563871 & AP2 domain-containing TF & 933 & 45.39 & 12.78 & 3.55 \\
\hline SIAP2_3 & 7031 & SGN-U563215 & DREB subfamily A-1 of ERF/AP2 TF family & 981 & 5.95 & 1.42 & 4.19 \\
\hline SIAP2_7 & 7865 & SGN-U587768 & DREB subfamily A-4 of ERF/AP2 TF family & 775 & 2.2 & 0.71 & 3.09 \\
\hline SIAP2_4 & 10714 & SGN-U586437 & $\begin{array}{l}\text { ERF (ethylene response factor) subfamily } \\
\text { B-3 of ERF/AP2 TF family }\end{array}$ & 611 & 2.72 & 0.71 & 3.83 \\
\hline SIAP2_10 & 14672 & SGN-U585539 & AP2 domain-containing TF & 297 & 18.87 & 7.99 & 2.36 \\
\hline SIAP2_5 & 16204 & SGN-U577088 & $\begin{array}{l}\text { ERF (ethylene response factor) subfamily } \\
\text { B-4 of ERF/AP2 TF family }\end{array}$ & 523 & 0.68 & 0.18 & 3.78 \\
\hline SIAP2_11 & 25582 & SGN-U584756 & $\begin{array}{l}\text { ERF (ethylene response factor) subfamily } \\
\text { B-2 of ERF/AP2 TF }\end{array}$ & 660 & 1.19 & 0.53 & 2.24 \\
\hline SIAP2_1 & 25985 & SGN-U586438 & $\begin{array}{l}\text { ERF (ethylene response factor) subfamily } \\
\text { B-3 of ERF/AP2 TF family }\end{array}$ & 942 & 16.32 & 0.53 & 30.8 \\
\hline SIAP2_8 & 26482 & SGN-U581852 & $\begin{array}{l}\text { Ethylene-responsive element-binding } \\
\text { factor } 4 \text { homolog }\end{array}$ & 788 & 58.81 & 24.32 & 2.42 \\
\hline SIWRKY22 & 9827 & SGN-U565154 & WRKY family TF & 1366 & 0.68 & 0.18 & 3.78 \\
\hline SIWRKY28 & 10561 & SGN-U584367 & WRKY family TF & 1326 & 0.5 & 0.18 & 2.78 \\
\hline SIWRKY78 & 13200 & SGN-U565157 & WRKY family TF & 1099 & 1.19 & 0.18 & 6.61 \\
\hline SIWRKY73 & 20918 & SGN-U571278 & WRKY family TF & 1453 & 0.5 & 0.18 & 2.78 \\
\hline SIMYC1 & 24332 & SGN-U576396 & MYC TF & 2174 & 32.47 & 22.7 & 1.43 \\
\hline
\end{tabular}

*Expression values are in RPKM (reads per kilobase of transcript per million mapped reads). 

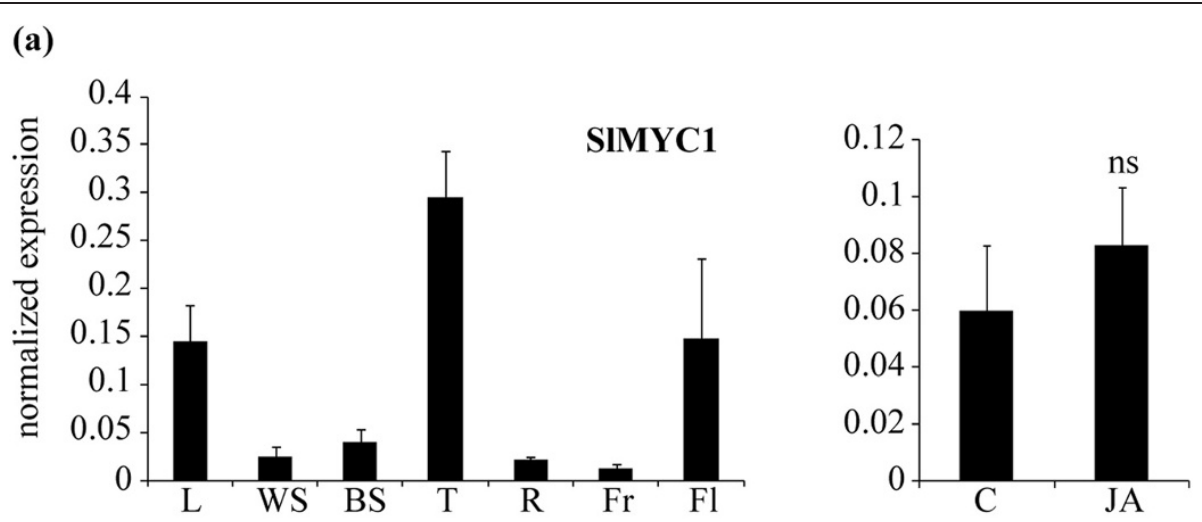

(b)
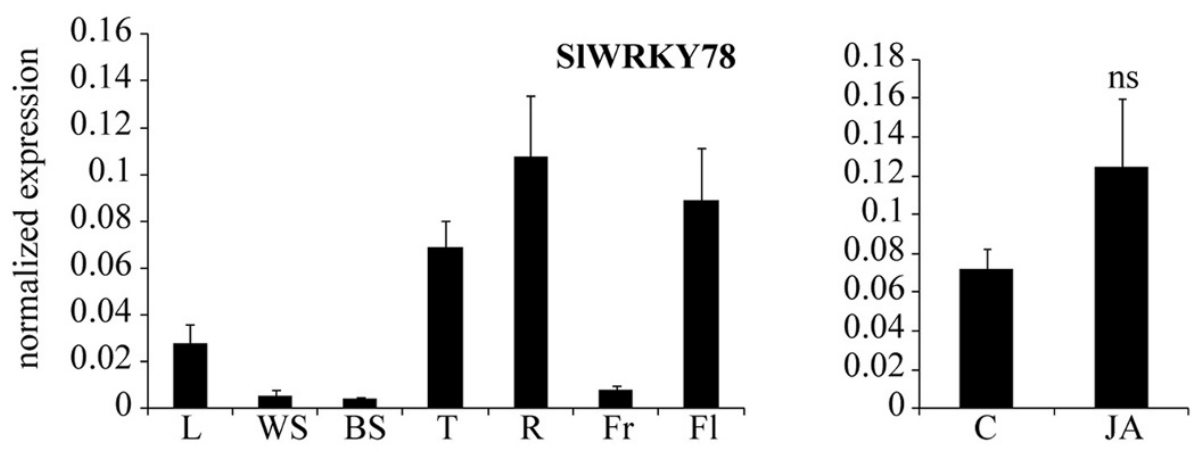

(c)
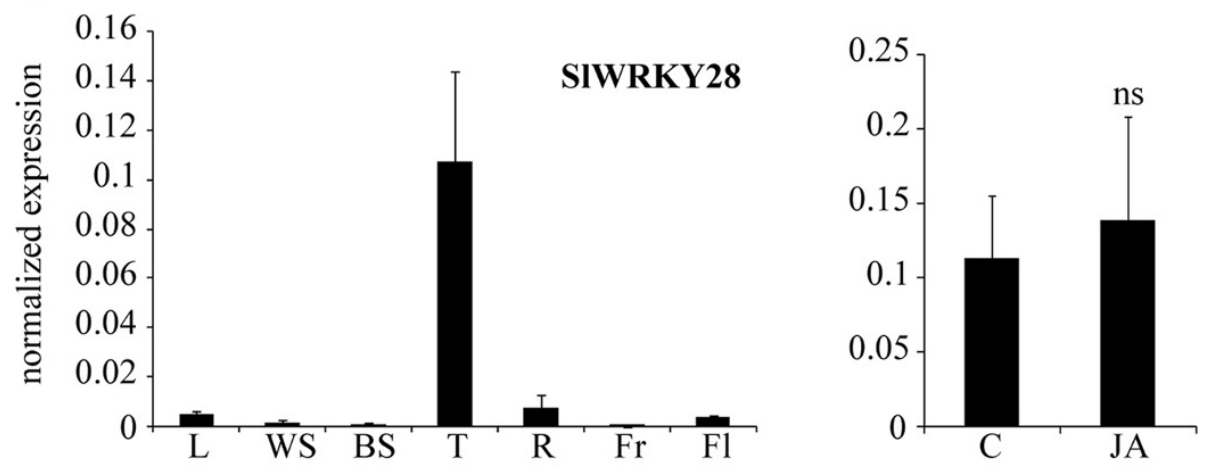

(d)
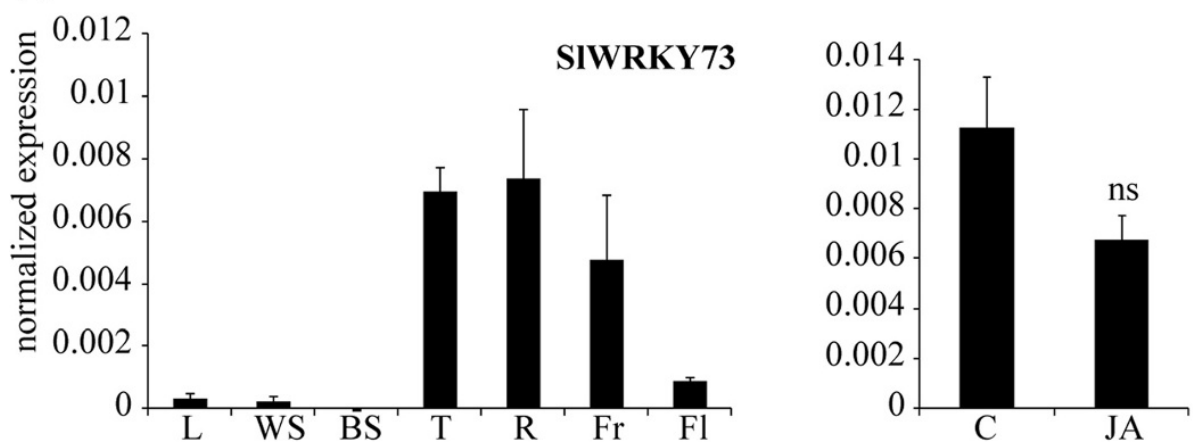

Figure 2 (See legend on next page.) 
(See figure on previous page.)

Figure 2 Tissue specific expression and JA induction of selected TFs. Transcript levels for (a) SIMYC1 (b) SIWRKY78, (c) SIWRKY 28 and (d) SIWRKY73 as determined by Q-RT-PCR. Mean values (+SE) of 3 biological replicas are shown, normalized for Actin expression. L; leaf, WS; whole stem, $B S$; bald stem, $T$; stem trichomes, $R$; root, $F r$; fruit, $F$; flower; $C$; control and JA; jasmonic acid induced stem trichomes. $n s$; not significant according to $T$-test.

As shown in Figure 3a, SIWRKY73 could transactivate the SITPS5 promoter, albeit to a lower extent than SIEOT1. SIWRKY73 transactivated the SITPS3 and SITPS7 promoters only weakly, and the SITPS8 and SITPS9 promoters not at all (35S:RFP negative controls shown in Additional file 1: Figure S2). SIWRKY78 or SIWRKY28 did not transactivate any of the terpene synthase promoters (Additional file 1: Figure S3).

SIMYC1 could transactivate all terpene synthase promoters tested except SITPS8. Transactivation of the trichome-specific SITPS5 and SITPS3 promoters was strongest (Figure 3b; 35S:RFP negative control shown in Additional file 1: Figure S2). However, it should be noted that GUS activity of a promoter driving the GUSsYFP1 fusion was lower than when the same promoter driving GUS alone was transactivated by an effector construct (data not shown), possibly because the fusion protein was less stable or produced. Therefore, transactivation by SIMYC1 of the trichome-specific SITPS9 promoter was potentially stronger than that detected here.

\section{SIMYC1 and SIEOT1 act synergistically on the SITPS5 promoter in $N$. benthamiana leaves}

Since SIEOT1, SIMYC1 and SIWRKY73 were shown in separate experiments to be able to transactivate the SITPS5 promoter (Figure 3), we investigated what effect a combination of these transcription factors would have on the transactivation of this promoter. To this end, Agrobacterium cultures carrying the CaMV 35S-driven effector constructs were mixed in pairs or all three together and combined with the SITPS5p: GUS reporter construct and infiltrated in $N$. benthamiana leaves

(a)

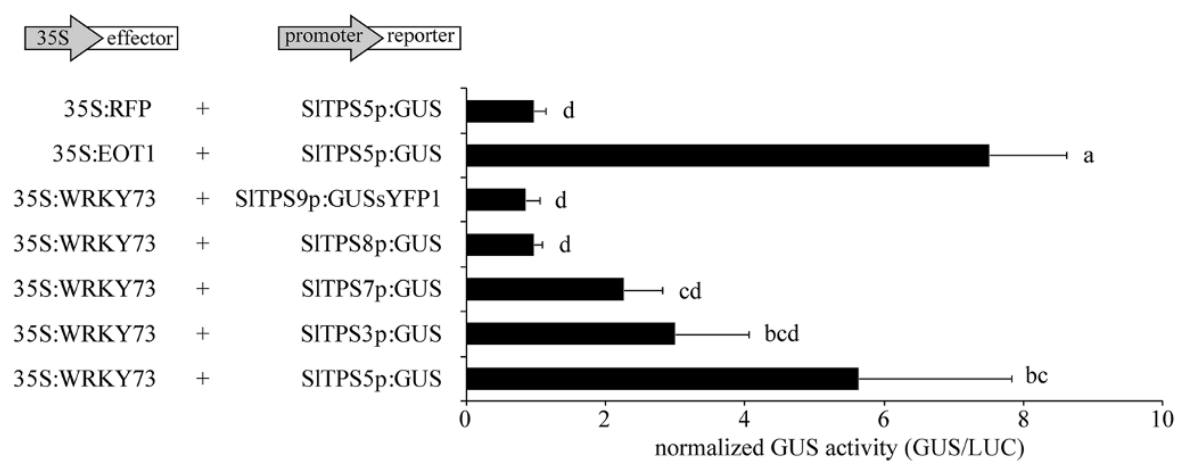

(b)

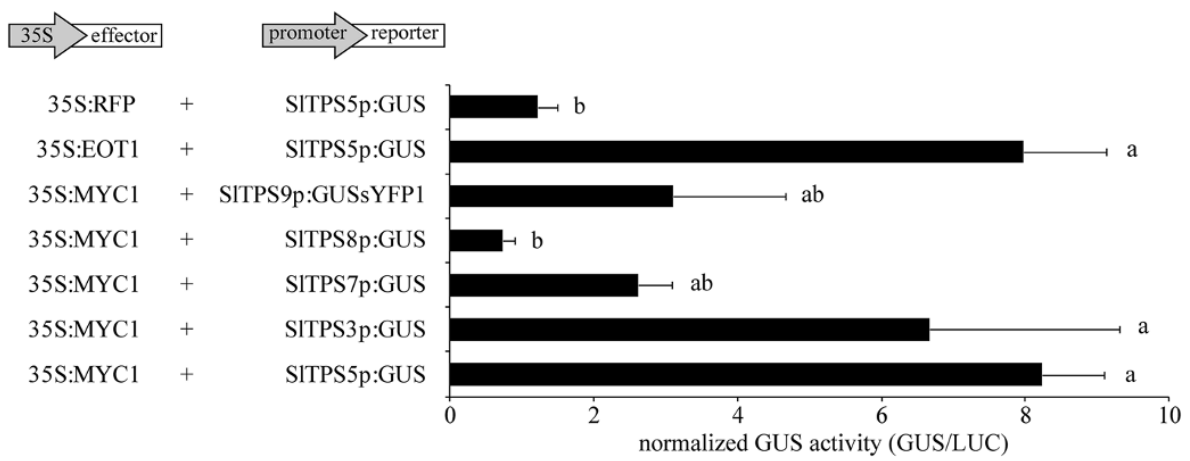

Figure 3 Transactivation of terpene synthase promoters by SIMYC1 and SIWRKY73 in N. benthamiana leaves. Normalized GUS activity after co-infiltration with A. tumefaciens harboring the (a) 35S:WRKY73 or (b) 35S:MYC1 effector construct and various promoter:GUS reporter constructs. The 35S:SIEOT1 and 35S:RFP effector constructs were used as positive and negative control, respectively. The bars represent the obtained mean values and the error bars the standard error $(n=3)$. RFP; red fluorescent protein. Letters indicate significant differences (ANOVA, $P<0.05$ according to Tuckey's B posthoc test). Representative results from three experiments are shown. 
(Figure 4). Interestingly, co-expression of SIEOT1 and SIMYC1 almost tripled the transactivation of SITPS5 promoter compared to the effect of each TF alone. Adding SlWRKY73 did not have an additional effect, but rather seemed to have a negative effect on the combinatorial action of the other two TFs, although not at a statistically significant level (Figure 4).

\section{Discussion and conclusions}

RNA sequencing of S. lycopersicum stem trichomes led to the identification of one MYC bHLH and one WRKY transcription factor that can transactivate several terpene synthase promoters. The observation that SIMYC1 acts synergistically with SIEOT1 in the transactivation of the SITPS5 promoter suggests a complex regulatory network for terpene biosynthesis.

\section{High-throughput sequencing of Solanum lycopersicum stem trichomes}

We used massive parallel pyrosequencing on the 454 GS FLX Titanium platform to sequence S. lycopersicum stem trichome RNAs with the goal to identify transcription factors involved in terpene biosynthesis. We used normalized cDNA to maximize representation of low abundant transcripts and reduce representation of highly abundant transcripts. Attempts to map the obtained reads to the publicly available mixed tissue SGN database led to a high percentage of unmapped reads and assignment of the same reads to multiple unigenes and therefore the reads were assembled de novo. $2.5 \%$ of the reads could not be matched and were not used in further analysis. $87.9 \%$ of the resulting contigs were subsequently annotated after blasting against the SGN tomato database using a local E-Blast tool. In this database we identified annotated enzymes involved in several metabolic pathways (Additional file 1: Table S1). In short, compared to the study published by McDowell and colleagues [3] on S. lycopersicum cv. M82 trichomes, we identified in Moneymaker trichomes
cDNAs encoding enzymes involved in for example the TCA cycle, starch and sucrose metabolism (Additional file 1: Table S1), as well as secondary metabolite biosynthesis (Table 2). Photosynthesis related genes were also identified but were not as prevalent (Additional file 1: Table S1) as in M82 trichomes. Such differences could originate from the fact that in our study we used a mix of Moneymaker trichome types, including stalks, whereas McDowell and colleagues focused on comparing different types of trichomes between Solanum species and so clipped off and analyzed only the secretory cells of glandular trichomes [3].

Furthermore we created an expression profiling database using Illumina sequencing in order to obtain genes regulated by JA. The success of the JA treatment is evident by the high induction of known JA markers, some of which are presented in Table 3 (LOXA, AOC [38]; JAZ1 [39]; JAZ3 [40]).

\section{Jasmonic acid regulation of the terpene biosynthesis pathway in tomato trichomes}

In order to investigate whether in stem trichomes of tomato Moneymaker plants, regulation of terpene biosynthesis by JA is also on the precursor level besides on the level of individual TPSs [21], the quantitative database was mined for enzymes of the precursor pathways. The copy number of these genes varies between different plant species [41] and, as shown in Table 4, different family members can vary in their expression levels and/or JA-inducibility. For example 1-deoxy-d-xylulose 5-phosphate synthase (DXS), in contrast with Arabidopsis, which contains a single functional gene, has diversified into two isogenes in other plant species including tomato [48]. Whereas SIDXS1 is ubiquitously expressed, SIDXS2 is expressed only in a few tissues and in leaf trichomes its transcript abundance is much higher than that of SIDXS1 [49], although this is not the case in stem trichomes (Table 4). Furthermore, SIDXS2 is moderately induced by

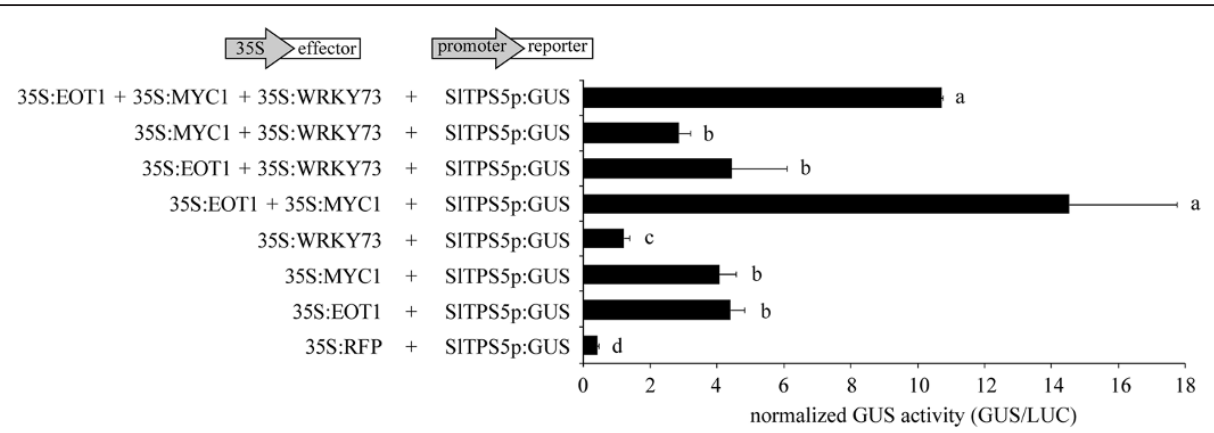

Figure 4 Transactivation of SITPS5 promoter by SIEOT1, SIMYC1, SIWRKY73 or combination thereof in N. benthamiana leaves. Normalized GUS activity after co-infiltration with A. tumefaciens harboring the 35S:EOT1, 35S:MYC1, 35S:WRKY73 effector constructs or combination thereof and the SITPS5p:GUS reporter construct. The 35S:RFP effector construct was used as negative control. The bars represent the obtained mean values and the error bars the standard error $(n=4)$. RFP; red fluorescent protein. Letters indicate significant differences (ANOVA, $P<0.05$ according to Tuckey's B posthoc test). Representative results from two experiments are shown. 
wounding in the cultivar Moneymaker [49], which correlates with the observed moderate induction of SIDXS2 by JA ( 1.6-fold, Table 4). SIDXS2 expression is also approximately threefold upregulated in the tomato cultivar Castlemart upon feeding by Manduca sexta larvae [50].

The regulation of precursor genes of the MEP pathway by wounding, hormones or elicitors has been demonstrated in various plant species [49-54]. Similarly, evidence for the regulation of precursor biosynthesis of the mevalonate (MVA) pathway is also abundant [55-60]. For example, HMGR enzyme activity and protein level were shown to increase by fungal infection in potato tubers and sweet potato root [59]. Furthermore, HMGR1 expression was induced by treatment with MeJA in potato, whereas HMGR2 expression was reduced [56]. In response to caterpillar herbivory, transcripts of HMGR1 were reduced in alfalfa [60]. Our results show that in tomato stem trichomes HMGR1 and HMGR3 were induced by JA treatment approximately 2-fold, whereas expression of HMGR2 remained unaltered (Table 4). None of the prenyl diphosphate synthases were induced in tomato trichomes by JA treatment, whereas two seemed to be downregulated (FPS, SGN-U578686; and GGPS, SGN-U573348; Table 4). We did not find any transcripts for GGPS1 (SGN-U574849) in our stem trichome database, although it has been shown to be induced in tomato leaves by JA-treatment [61]. Finally, from the very recently identified cis-prenyltransferases only CPT5, that produces medium-length chain polyisoprenoids [62], was upregulated by JA, 1.7-fold (Table 4).

\section{Identification of transcription factors involved in regulating terpene synthases in tomato trichomes}

Our primary aim was to identify transcription factor(s) that regulate terpene biosynthesis. Based on the annotated contigs, $2.7 \%$ of the transcripts in the tomato stem trichomes encode transcription factors. For comparison, in Arabidopsis thaliana $6 \%$ of the genes in all tissues encode TFs (TAIR10 genome release, [63]). Since JA is essential for establishing indirect defense responses in tomato $[34,35]$ and the induction of terpene synthases in trichomes [16,21], we hypothesized that TFs involved in the regulation of terpene biosynthesis would also be JAinducible genes. Most of the transcription factors known to be involved in regulation of terpenoid pathways are jasmonate-inducible and of the APETALA2, WRKY or MYC class [25-30,33]. However, in Arabidopsis it was recently shown that two MYC transcription factors (AtMYC3 and AtMYC4), which act additively with AtMYC2 in the activation of JA responses, are, in contrast to $A t M Y C 2$, only marginally induced by JA treatment [64]. Based on all the above, the initial selection of transcription factors to be analyzed from our quantitative stem trichome database was limited to TFs of the AP2, WRKY and MYC class that showed a 2-fold or higher induction by JA treatment (2.2-fold was the induction rate of control gene SlMTS1; [16], renamed SlTPS5 [21]; Table 5). None of the MYC transcription factors of our database showed induction higher than 2, so for further analysis the closest homolog of AtMYC2 [32] was selected, as it has been shown to activate the AtTPS11 and AtTPS21 promoters [33]. After discarding TFs that were not trichome-specific or did not show highest expression in trichomes, the list was narrowed down to four candidate transcription factors. According to the Q-RT-PCR data however, none of these TFs was significantly induced by JA treatment (Figure 2). Since the numbers of sequence reads of these genes is very low both in the Control and JA samples (Table 6), the fold-induction in the Illumina experiments must have been overestimated.

\section{SIMYC1 and SIWRKY73 transactivate terpene synthase promoters in planta}

A specific indication of whether any of these TFs are involved in regulating terpene biosynthesis would be the activation of terpene synthase promoters by the transcription factor. In transient activation assays in N. benthamiana leaves two of the four selected transcription factors were able to transactivate at least one terpene synthase promoter. SIWRKY73 showed strongest transactivation of the SITPS5 promoter and in lesser extent of the SITPS3 and SlTPS7 promoters (Figure 3a). Although SlWRKY73 is expressed highly in roots (Figure 2), SIWRKY73 could not transactivate the promoter of SITPS8 that is mainly expressed in roots. It could also not transactivate the trichome-specific sesquiterpene synthase SITPS9 promoter so it is possible that SIWRKY73 can transactivate only monoterpene synthases or at least not the sesquiterpene synthase tested here (Figure 3a). As shown in Figure 5 SlWRKY73 and the respective TPSs that it can transactivate are co-expressed in various tissues where the regulation could take place in the plant.

SIMYC1 showed strongest transactivation of SITPS5 and SlTPS3 and to a lesser extent of SlTPS7 and SlTPS9 but no transactivation of SITPS8 promoter (Figure 3b), although SIMYC1 is also expressed in the root, albeit not strongly (Figure 2). As shown in Figure 5 SIMYC1 is expressed (at different levels) in every plant tissue and SIMYC1 is able to activate all the terpene synthase promoters tested except one, so it seems to be a regulator of multiple TPSs, in contrast to SIEOT1 that is only expressed in the glandular trichomes and can specifically transactivate the SITPS5 promoter and none of the other TPS promoters tested (Figure 5, [47]). The other two selected TFs (SIWRKY78 and SIWRKY28; Additional file 1: Figure S3) were not able to significantly transactivate any of the tested terpene synthase promoters. However it cannot be excluded that these TFs were not expressed in the transient assay. 


\begin{tabular}{|c|c|c|c|c|c|c|}
\multicolumn{1}{c|}{$(\mathbf{a})$} & Leaf & Stem & Trichomes & Root & Fruit & Flower \\
\hline SIMYC1 & + & $+/-$ & ++ & $+/$ & $+/-$ & + \\
\hline SITPS5 & -- & -- & ++ & -- & -- & - \\
\hline SITPS3 & -- & -- & ++ & $+/-$ & -- & $+/-$ \\
\hline SITPS7 & + & +- & -- & +- & -- & ++ \\
\hline SITPS8 & -- & -- & -- & ++ & -- & -- \\
\hline SITPS9 & -- & -- & +++ & -- & -- & - \\
\hline
\end{tabular}

\begin{tabular}{c|c|c|c|c|c|c|}
\cline { 2 - 7 } \multicolumn{1}{c|}{$(\mathbf{b})$} & Leaf & Stem & Trichomes & Root & Fruit & Flower \\
\hline SIWRKY73 & -- & -- & ++ & ++ & + & $+/-$ \\
\hline SITPS5 & -- & -- & ++ & -- & -- & -- \\
\hline SITPS3 & -- & -- & ++ & $+/-$ & -- & $+/-$ \\
\hline SITPS7 & + & +- & -- & $+/-$ & -- & ++ \\
\hline SITPS8 & -- & -- & -- & ++ & -- & -- \\
\hline SITPS9 & -- & -- & +++ & -- & -- & -- \\
\hline
\end{tabular}

\begin{tabular}{|c|c|c|c|c|c|c|}
\cline { 2 - 7 } \multicolumn{1}{c|}{$(c)$} & Leaf & Stem & Trichomes & Root & Fruit & Flower \\
\hline SIEOT1 & -- & -- & + & -- & -- & - \\
\hline SITPS5 & -- & -- & ++ & -- & -- & -- \\
\hline SITPS3 & -- & -- & ++ & $+/-$ & -- & $+/-$ \\
\hline SITPS7 & + & $+/-$ & -- & $+/$ & -- & ++ \\
\hline SITPS8 & -- & -- & -- & ++ & -- & -- \\
\hline SITPS9 & -- & -- & +++ & -- & -- & -- \\
\hline
\end{tabular}

Figure 5 Expression patterns and activation overview of TFs and TPSs. Putative positive interaction of the respective SITPS promoters by transcription factors (a) SIMYC1, (b) SIWRKY73 and (c) SIEOT1 is indicated by a colored box that represents the tissue in which they are co-expressed. Expression in the various tissues is indicated by,,,$+++++++/-$ and - according to Q-RT-PCR values. Darker shaded boxes indicate a stronger transient activation of the TPS promoter by the TF in N. benthamiana leaves. EOT1; Expression of Terpenoids 1 [47].

One question that arises is, of course, where SlWRKY73 and SIMYC1 bind on these terpene synthase promoters. In the promoter sequence of SITPS5, SITPS3 and SITPS7 [47] there are five, four and one W-boxes $(\mathrm{TGAC}(\mathrm{C} / \mathrm{T}))$ respectively (PLACE; [65], Additional file 1: Table S2), which could serve as potential binding site(s) for SIWRKY73. Furthermore, SITPS5 promoter contains two G-box-like elements (CACATG instead of the canonical CACGTG), one T/G-box element (AACGTG) and one T/G-box-like element (TACGTG) (Additional file 1: Table S2), which could potentially be the binding site(s) of SIMYC1. The promoter of SITPS3, with which SIMYC1 interacts less strongly, contains one G-box-like element and one T/Gbox element (Additional file 1: Table S2). The SITPS7 promoter, which SIMYC can also activate, contains one T/G-box (Additional file 1: Table S2). The SlTPS9 promoter [47] however, does not contain any of these elements, which could indicate the existence of an uncharacterized motif to which SIMYC1 binds. When using the motif search program MEME [66] with all four promoters that SIMYC1 can activate, one $8 \mathrm{bp}$ motif was identified in the plus or minus (for SlTPS9) orientation: CTAGG(T/A) $(\mathrm{A} / \mathrm{G}) \mathrm{G}$. The validation of a (putative) regulatory element as the binding site for these TFs would require extensive further experimentation. However, since our transactivation assays do not indicate direct binding, the TF-TPS promoter interactions observed in the ATTAs, could take place through an additional protein. To address the issue of which terpene synthases (and possibly other genes as well) these TFs regulate, we are currently starting the more laborious but more conclusive approach of creating stably transformed silenced and overexpressing plants.

\section{SIMYC1 acts synergistically with SIEOT1 in the transactivation of the SITPS5 promoter}

Interestingly, SIEOT1 and SIMYC1 acted synergistically in the transactivation of the SITPS5 promoter (Figure 4). Combinatorial control of transcriptional regulation is commonly found in plants and other eukaryotes [67]. For example, in abscisic acid (ABA) signaling, the $67 \mathrm{bp}$ promoter region of the dehydration-responsive gene $r d 22$ contains a MYC and a MYB recognition site, where 
AtMYC2 and AtMYB2 can bind, respectively. In Arabidopsis leaf protoplasts it was shown that these TFs could individually activate transcription of $\beta$-glucuronidase driven by this $67 \mathrm{bp}$ promoter region of $r d 22$ and that the transient activation was stronger when AtMYC2 and AtMYB2 were combined [68]. Transgenic plants overexpressing these TFs each showed ABA hypersensitivity but the effect was more profound in plants overexpressing both TFs [69].

Given the fact that SIMYC1 and SlEOT1 are not induced by JA (Figure 2, [47]) and yet the proteins can transactivate the JA-inducible SITPS5 promoter indicates that they could be regulating the steady-state transcription of SITPS5. These TFs might however also be involved in the enhanced SITPS5 expression by interacting with other, inducible TF(s). From the well-studied cases of transcriptional regulation in Catharanthus roseus [25-27] and Arabidopsis $[32,33,64]$ it has becomes clear that it usually involves a network of TFs. In Solanum lycopersicum we are only just starting to unravel the complexity of transcriptional regulation of terpene biosynthesis.

\section{Methods}

\section{Hormone treatment and RNA isolation}

Tomato plants (Solanum lycopersicum cultivar Moneymaker) were grown in soil in a greenhouse with day/night temperatures of $23^{\circ} \mathrm{C} / 18^{\circ} \mathrm{C}$ and a $16 / 8 \mathrm{~h}$ light/dark regime for four weeks. They were then sprayed either with JA solution (1 mM JA; Duchefa, NL, in tap water + 0,05\% SilwetL-77; GE Silicones, VA, USA) or with control solution $(0,05 \%$ SilwetL-77 in tap water). Stem pieces were collected $30 \mathrm{~min}, 2 \mathrm{~h}, 8 \mathrm{~h}$ and $24 \mathrm{~h}$ later for pyrosequencing or $24 \mathrm{~h}$ later for expression analyses and trichomes were isolated by shaking the stems in liquid nitrogen. Total RNA was isolated using TRIzol (Invitrogen, Paisley, UK) according to the manufacturer's instructions. Equal amount of trichome RNA from the different time points was pooled creating the control (C) and JA samples. RNA used for pyrosequencing was then purified on a RNeasy Plant column (Qiagen, Valencia, CA, USA).

\section{Transcriptome database construction}

RNA quality was determined with the Agilent RNA pico chip (Agilent Technologies, Waldbronn, Germany). Synthesis and amplification of cDNA was performed using the SMART PCR cDNA Synthesis and Advantage 2 PCR kits (Clontech Inc., CA, USA) according to the manufacturer's instructions with some modifications of adapters to eliminate 3' poly(A)-stretches prior to sequencing. cDNA quality was determined with the Agilent DNA 7500 chip (Agilent Technologies, Waldbronn, Germany) or on an 1\% agarose/EtBr gel. Normalization of the cDNA was carried out using the Evrogen TRIMMER kit (Evrogen, Moscow, Russia) according to the manufacturer's protocol. The normalization efficiency was determined both on an
agarose/EtBr gel (1\%) and with an Agilent DNA 7500 chip. The cDNA was purified and concentrated using the Qiaquick PCR purification kit (Qiagen, Valencia, CA, USA). cDNA shearing and FLX Titanium library preparation was carried out using the Roche GS FLX Titanium General Library Preparation Method kit (Roche Diagnostics, Mannheim, Germany) according to the manufacturer's protocol. The size range of the fragments was determined with an Agilent DNA 1000 chip (Agilent Technologies, Waldbronn, Germany). Exclusion of smaller-sized fragments was performed using the double SPRI method as described in the Roche GS FLX Titanium General Library Preparation protocol (Roche Diagnostics, Mannheim, Germany). End-polishing, small fragment removal, library immobilization, fill-in reaction and single-stranded library isolation was performed using the GS FLX Titanium General Library Preparation Method kit (454 Life Sciences, Roche Diagnostics, Mannheim, Germany) according to manufacturer's instructions.

\section{Expression profiling database construction}

Starting from the same total RNA samples (C and JA, see above), mRNA was amplified and purified using the MessageAmp II aRNA Amplification kit (Applied Biosystems/ Ambion, CA, USA) according to manufacturer's instructions. RNA quality was determined with the Agilent RNA pico chip (Agilent Technologies, Waldbronn, Germany). Synthesis of cDNA was performed using the MessageAmp II aRNA Amplification kit (Applied Biosystems/Ambion, CA, USA) according to manufacturer's instructions with modifications of the adapters to enable sequencing of 3' cDNA ends. cDNA was purified with the Qiaquick PCR purification kit (Qiagen, Valencia, CA, USA). cDNA quality was determined with the Agilent DNA 7500 chip (Agilent Technologies, Waldbronn, Germany) or on an $1 \%$ agarose $/ \mathrm{EtBr}$ gel. Shearing and ligation was carried out using standard Illumina PE adapters containing a specific sample ID tag. Adapter-ligated cDNA fragments were column purified with the Qiaquick PCR purification kit (Qiagen, Valencia, CA, USA). The size range of the fragments was determined with an Agilent DNA 1000 chip (Agilent Technologies, Waldbronn, Germany). Exclusion of smaller-sized fragments was performed using a single SPRI procedure as described in the Agencourt Ampure PCR Purification protocol (Agencourt Bioscience Corporation, MA, USA). The size range of single-stranded fragments was determined with an Agilent RNA pico 6000 chip (Agilent Technologies, Waldbronn, Germany). Expression profiling was performed using the Illumina Genome Analyzer II System (Illumina, USA).

Databases assembly, EST annotation and homology searches The 454 sequencing reads (Control and JA combined) were assembled into contigs de novo by Vertis Biotechnologie 
AG, Germany using the CLCbio software [70]. Nucleotide sequences of the contigs were then blasted against the SGN unigenes v2 tomato database (ftp.solgenomics.net/unigene builds/combined_species_assemblies/tomato_species) for annotation, using a local Eblast tool ( $E$ value $1 \mathrm{e}-9)$. The GA II reads (Control and JA separately) were mapped to the annotated contigs of the 454 sequencing trichome database by Vertis Biotechnologie AG, Germany.

The resulting contigs were also imported in the bioinformatics tool Blast2GO v.2.5.0 [37] and were blasted against the National Center for Biotechnology Information (NCBI) non-redundant protein database BLASTX ( $E$ value $1 \mathrm{e}-3)$. Further analyses with this tool included functional annotation by Gene Ontology (GO) terms and Enzyme Commission numbers (EC code), InterPro terms (InterProScan; [71]) and metabolic pathways (Kyoto Encyclopedia of Genes and Genomes, KEGG; [72]).

\section{cDNA synthesis and quantitative-real time-PCR}

DNA was removed from RNA with DNAse (Ambion, Huntingdon, UK) according to the manufacturer's instuctions and cDNA was synthesized from $1.5 \mu \mathrm{g}$ RNA using M-MuLV $\mathrm{H}^{-}$Reverse Transcriptase (Fermentas, St. Leon-Rot, Germany). For Q-RT-PCR, cDNA equivalent to $100 \mathrm{ng}$ total RNA was used as template in $20 \mu \mathrm{l}$ volume and reactions were performed in the ABI 7500 Real-Time PCR System (Applied Biosystems) using the Platinum SYBR Green qPCR SuperMix-UDG kit (Invitrogen, Paisley, UK) with the following cycling program: $2 \mathrm{~min} 50^{\circ} \mathrm{C}, 7 \mathrm{~min} 95^{\circ} \mathrm{C}, 45$ cycles of $15 \mathrm{sec}$ at $95^{\circ} \mathrm{C}$ and $1 \mathrm{~min}$ at $60^{\circ} \mathrm{C}$, followed by a melting curve analysis. Primer pairs were tested for amplification kinetics and linearity with a standard cDNA dilution curve and new primers were designed if necessary. Expression levels were normalized using ACTIN (SGN-U579547) mRNA levels. Effects of JA on gene expression were analyzed in three biological replicates by $T$-test using PASW Statistics 17.0 [73]. The homogeneity of variance was tested by Levene's test.

\section{Cloning, construct design and ATTAs}

TFs SlMYC1 (KF430611; sequence of the full-length ORF obtained from the 454 trichome database), SlWRKY28 and SlWRKY73 ([74]; Additional file 1: Figure S4) were cloned between restriction sites $\mathrm{NcoI}$ (at the ATG) and $\mathrm{SacI}$ (at the $3^{\prime}$ end of the sequence) in front of the Nos terminator in vector pKG1662 (KeyGene, Wageningen, NL; for a map of the vector see patent $\mathrm{nr}$ US2011/0113512A1) driven by the CaMV 35S promoter. TF SlWRKY78 ([74]; Additional file 1: Figure S4) was cloned downstream of the CaMV 35S promoter in vector pJVII, a pMON999based vector (Monsanto, St. Louis, MO) with a modified multiple cloning site (MCS), between restriction sites $\mathrm{Xba \textrm {I }}$ (at the ATG) and BsrGI (at the 3' end of the sequence).
All constructs were verified by sequencing and then the expression cassettes containing 35S promoter, cDNA of interest and nos terminator were transferred to the MCS of the binary vector pBINplus [75] between HindIII and SmaI restriction sites. The final constructs were transformed to Agrobacterium tumefaciens GV3101 (pMP90). The promoter:GUS constructs used in the transient transactivation assay have been described elsewhere [47]. The A. tumefaciens transient transactivation assay (ATTA) was performed as described in Spyropoulou et al., [47].

\section{Additional file}

Additional file 1: Figure S1. Gene ontology (GO) and enzyme classifications (EC) for S. lycopersicum stem trichome transcriptome at level 2. (a) Cellular component GO terms, (b) biological process GO terms, (c) molecular function GO terms and (d) general EC terms. Figure S2. Transactivation of terpene synthase promoters by 35S:RFP in N. benthamiana leaves. Letters indicate significant differences $(n=4$, ANOVA, $P<0.05$ according to Tuckey's B posthoc test). The normalized GUS activity of the SITPS3, 7, 8 and 9 reporter constructs with the RFP effector construct is not significantly higher from the SITPS5 reporter construct with the RFP effector construct, indicating that any relevant activation of an effector construct (in Figures 3, 4, and Additional file 1: Figure S3) must be significantly higher than that of the SITPS5p:GUS reporter- 35S:RFP effector combination. Figure S3. Transactivation of terpene synthase promoters by SIWRKY78 and SIWRKY28 in N. benthamiana leaves. Letters indicate significant differences ( $n=3$, ANOVA, $P<0.05$ according to Tuckey's B posthoc test). Representative results from two experiments are shown. The normalized GUS activity of the 35S:WRKY28 effector- SITPS5p:GUS reporter construct combination was only marginally higher than that of the negative control (35S:RFP effector- SITPS5p:GUS reporter constructs) and was not further investigated. Figure S4. Nucleotide sequence of transcription factors SIWRKY78 (Solyc07g055280.2.1), SIWRKY28 (Solyc12g011200.1.1), SIWRKY73 (Solyc03g113120.2.1) and SIMYC1 (KF430611). The predicted coding sequences are in capital letters, $5^{\prime}$ and $3^{\prime}$ UTRs are in small letter type. Start and stop codons are in bold. Table S1. KEGG pathways found in the S. lycopersicum stem trichome transcriptome. Table S2. Selected regulatory motifs in the sequence of SITPS5, 3 and 7 promoters analyzed by PLACE [65]. Table S3. List of primers used.

\section{Abbreviations}

TPS: Terpene synthase; TF: Transcription factor; EOT1: Expression of terpenoids 1; SGN: Solanaceae genomics network; JA: Jasmonic acid.

\section{Competing interests}

The authors declare no competing interest. Regulation of terpenoid production through the use of the EOT1 gene and its application for enhanced insect resistance are protected by patents and/or patent applications owned by Keygene N.V. (WO2012169893).

\section{Authors' contributions}

EAS performed the experiments and wrote the manuscript. RCS coordinated the research and corrected the manuscript. MAH revised the manuscript. All authors read and approved the final manuscript.

\section{Acknowledgments}

We thank Raymond Hulzink (KeyGene, Wageningen, NL) for the preparation of the transcriptome and expression profiling libraries, Carlos A. Villarroel Figueroa for help with the bioinformatics, Juan M. Alba Cano for help with the statistical analyses and Harold Lemeris, Ludeck Tikovsky and Thijs Hendrix for the excellent care of the plants. This work was supported by grant 1C002RP of the Technological Top Institute-Green Genetics with KeyGene as project leader. 
Received: 19 February 2014 Accepted: 9 May 2014

Published: 27 May 2014

\section{References}

1. Schilmiller AL, Last RL, Pichersky E: Harnessing plant trichome biochemistry for the production of useful compounds. Plant J 2008, 54(4):702-711.

2. Tissier A: Glandular trichomes: what comes after expressed sequence tags? Plant J 2012, 70(1):51-68.

3. McDowell ET, Kapteyn J, Schmidt A, Li C, Kang JH, Descour A, Shi F, Larson M, Schilmiller A, An L, Jones AD, Pichersky E, Soderlund CA, Gang DR: Comparative functional genomic analysis of Solanum glandular trichome types. Plant Physiol 2011, 155(1):524-539.

4. Schilmiller A, Shi F, Kim J, Charbonneau AL, Holmes D, Daniel Jones A, Last RL: Mass spectrometry screening reveals widespread diversity in trichome specialized metabolites of tomato chromosomal substitution lines. Plant J 2010, 62:391-403.

5. Besser K, Harper A, Welsby N, Schauvinhold I, Slocombe S, Li Y, Dixon RA, Broun P: Divergent regulation of terpenoid metabolism in the trichomes of wild and cultivated tomato species. Plant Physiol 2009, 149(1):499-514.

6. Xie Z, Kapteyn J, Gang DR: A systems biology investigation of the MEP/terpenoid and shikimate/phenylpropanoid pathways points to multiple levels of metabolic control in sweet basil glandular trichomes. Plant J 2008, 54(3):349-361.

7. Gang DR, Wang J, Dudareva N, Nam KH, Simon JE, Lewinsohn E, Pichersky E: An investigation of the storage and biosynthesis of phenylpropenes in sweet basil. Plant Physiol 2001, 125(2):539-555.

8. Cui H, Zhang ST, Yang HJ, Ji H, Wang XJ: Gene expression profile analysis of tobacco leaf trichomes. BMC Plant Biol 2011, 11:76.

9. Harada E, Kim JA, Meyer AJ, Hell R, Clemens S, Choi YE: Expression profiling of tobacco leaf trichomes identifies genes for biotic and abiotic stresses. Plant Cell Physiol 2010, 51(10):1627-1637.

10. Lange BM, Wildung MR, Stauber EJ, Sanchez C, Pouchnik D, Croteau R: Probing essential oil biosynthesis and secretion by functional evaluation of expressed sequence tags from mint glandular trichomes. Proc Natl Acad Sci U S A 2000, 97(6):2934-2939.

11. Aziz N, Paiva NL, May GD, Dixon RA: Transcriptome analysis of alfalfa glandular trichomes. Planta 2005, 221(1):28-38.

12. Wang W, Wang Y, Zhang Q, Qi Y, Guo D: Global characterization of Artemisia annua glandular trichome transcriptome using 454 pyrosequencing. BMC Genomics 2009, 10(1):465.

13. Wang G, Tian L, Aziz N, Broun P, Dai X, He J, King A, Zhao PX, Dixon RA: Terpene biosynthesis in glandular trichomes of hop. Plant Physiol 2008, 148(3):1254-1266.

14. Luo H, Li Y, Sun C, Wu Q, Song J, Sun Y, Steinmetz A, Chen S: Comparison of 454-ESTs from Huperzia serrata and Phlegmariurus carinatus reveals putative genes involved in lycopodium alkaloid biosynthesis and developmental regulation. BMC Plant Biol 2010, 10:209.

15. Bleeker PM, Spyropoulou EA, Diergaarde PJ, Volpin H, De Both MT, Zerbe P, Bohlmann J, Falara V, Matsuba Y, Pichersky E, Haring MA, Schuurink RC: RNA-seq discovery, functional characterization, and comparison of sesquiterpene synthases from Solanum lycopersicum and Solanum habrochaites trichomes. Plant Mol Biol 2011, 77(4-5):323-336.

16. van Schie CC, Haring MA, Schuurink RC: Tomato linalool synthase is induced in trichomes by jasmonic acid. Plant Mol Biol 2007, 64(3):251-263.

17. Bleeker PM, Diergaarde PJ, Ament K, Guerra J, Weidner M, Schutz S, de Both MT, Haring MA, Schuurink RC: The role of specific tomato volatiles in tomato-whitefly interaction. Plant Physiol 2009, 151(2):925-935.

18. Schilmiller AL, Schauvinhold I, Larson M, Xu R, Charbonneau AL, Schmidt A, Wilkerson C, Last RL, Pichersky E: Monoterpenes in the glandular trichomes of tomato are synthesized from a neryl diphosphate precursor rather than geranyl diphosphate. Proc Natl Acad Sci U S A 2009, 106(26):10865-10870.

19. Kang JH, Liu G, Shi F, Jones AD, Beaudry RM, Howe GA: The tomato odorless-2 mutant is defective in trichome-based production of diverse specialized metabolites and broad-spectrum resistance to insect herbivores. Plant Physiol 2010, 154(1):262-272.

20. Bleeker PM, Mirabella R, Diergaarde PJ, VanDoorn A, Tissier A, Kant MR, Prins M, de Vos M, Haring MA, Schuurink RC: Improved herbivore resistance in cultivated tomato with the sesquiterpene biosynthetic pathway from a wild relative. Proc Natl Acad Sci U S A 2012, 109(49):20124-20129.

21. Falara V, Akhtar TA, Nguyen TT, Spyropoulou EA, Bleeker PM, Schauvinhold I, Matsuba Y, Bonini ME, Schilmiller AL, Last RL, Schuurink RC, Pichersky E: The tomato terpene synthase gene family. Plant Physiol 2011, 157(2):770-789.

22. Matsuba Y, Nguyen TT, Wiegert K, Falara V, Gonzales-Vigil E, Leong B, Schafer P, Kudrna D, Wing RA, Bolger AM, Usadel B, Tissier A, Fernie AR, Barry CS, Pichersky E: Evolution of a complex locus for terpene biosynthesis in solanum. Plant Cell 2013, 25(6):2022-2036.

23. De Geyter N, Gholami A, Goormachtig S, Goossens A: Transcriptional machineries in jasmonate-elicited plant secondary metabolism. Trends Plant Sci 2012, 17(6):349-359.

24. Yang $C Q$, Fang $X$, Wu XM, Mao YB, Wang $L$, Chen $X Y$ : Transcriptional regulation of plant secondary metabolism. J Integr Plant Biol 2012, 54(10):703-712.

25. van der Fits $L$, Memelink J: ORCA3, a jasmonate-responsive transcriptional regulator of plant primary and secondary metabolism. Science 2000, 289(5477):295-297.

26. Zhang H, Hedhili S, Montiel G, Zhang Y, Chatel G, Pre M, Gantet P, Memelink J: The basic helix-loop-helix transcription factor CrMYC2 controls the jasmonate-responsive expression of the ORCA genes that regulate alkaloid biosynthesis in Catharanthus roseus. Plant J 2011, 67(1):61-71

27. Suttipanta N, Pattanaik S, Kulshrestha M, Patra B, Singh SK, Yuan L: The transcription factor CrWRKY1 positively regulates the terpenoid indole alkaloid biosynthesis in catharanthus roseus. Plant Physiol 2011, 157(4):2081-2093.

28. $X u$ YH, Wang JW, Wang S, Wang JY, Chen XY: Characterization of GaWRKY1, a cotton transcription factor that regulates the sesquiterpene synthase gene (+)-delta-cadinene synthase-A. Plant Physiol 2004, 135(1):507-515.

29. Ma D, Pu G, Lei C, Ma L, Wang H, Guo Y, Chen J, Du Z, Wang H, Li G, Ye H, Liu B: Isolation and characterization of AaWRKY1, an Artemisia annua transcription factor that regulates the amorpha-4,11-diene synthase gene, a key gene of artemisinin biosynthesis. Plant Cell Physiol 2009, 50(12):2146-2161.

30. Yu ZX, Li JX, Yang CQ, Hu WL, Wang LJ, Chen XY: The jasmonateresponsive AP2/ERF transcription factors AaERF1 and AaERF2 positively regulate artemisinin biosynthesis in Artemisia annua L. Mol Plant 2012, 5(2):353-365.

31. Lu X, Zhang L, Zhang F, Jiang W, Shen $Q$, Zhang L, Lv Z, Wang G, Tang K: AaORA, a trichome-specific AP2/ERF transcription factor of Artemisia annua, is a positive regulator in the artemisinin biosynthetic pathway and in disease resistance to Botrytis cinerea. New Phytol 2013, 198(4):1191-1202.

32. Lorenzo O, Chico JM, Sanchez-Serrano JJ, Solano R: JASMONATE-INSENSITIVE1 encodes a MYC transcription factor essential to discriminate between different jasmonate-regulated defense responses in Arabidopsis. Plant Cell 2004, 16(7):1938-1950.

33. Hong GJ, Xue XY, Mao YB, Wang $L$, Chen XY: Arabidopsis MYC2 interacts with DELLA proteins in regulating sesquiterpene synthase gene expression. Plant Cell 2012, 24(6):2635-2648.

34. Kant MR, Ament K, Sabelis MW, Haring MA, Schuurink RC: Differential timing of spider mite-induced direct and indirect defenses in tomato plants. Plant Physiol 2004, 135(1):483-495.

35. Ament K, Kant MR, Sabelis MW, Haring MA, Schuurink RC: Jasmonic acid is a key regulator of spider mite-induced volatile terpenoid and methyl salicylate emission in tomato. Plant Physiol 2004, 135(4):2025-2037.

36. Blast2Go. http://www.blast2go.com

37. Conesa A, Gotz S, Garcia-Gomez JM, Terol J, Talon M, Robles M: Blast2GO: a universal tool for annotation, visualization and analysis in functional genomics research. Bioinformatics 2005, 21(18):3674-3676.

38. Li L, Zhao Y, McCaig BC, Wingerd BA, Wang J, Whalon ME, Pichersky E, Howe GA: The tomato homolog of CORONATINE-INSENSITIVE1 is required for the maternal control of seed maturation, jasmonatesignaled defense responses, and glandular trichome development. Plant Cell 2004, 16(1):126-143.

39. Thines B, Katsir L, Melotto M, Niu Y, Mandaokar A, Liu G, Nomura K, He SY, Howe GA, Browse J: JAZ repressor proteins are targets of the SCF(COI1) complex during jasmonate signalling. Nature 2007, 448(7154):661-665. 
40. Katsir L, Schilmiller AL, Staswick PE, He SY, Howe GA: COI1 is a critical component of a receptor for jasmonate and the bacterial virulence factor coronatine. Proc Natl Acad Sci U S A 2008, 105(19):7100-7105.

41. Tholl D, Lee S: Terpene specialized metabolism in Arabidopsis thaliana. Arabidopsis Book 2011, 9:e0143

42. Sapir-Mir M, Mett A, Belausov E, Tal-Meshulam S, Frydman A, Gidoni D, Eyal Y: Peroxisomal localization of Arabidopsis isopentenyl diphosphate isomerases suggests that part of the plant isoprenoid mevalonic acid pathway is compartmentalized to peroxisomes. Plant Physiol 2008 148(3):1219-1228

43. Simkin AJ, Guirimand G, Papon N, Courdavault V, Thabet I, Ginis O, Bouzid S, Giglioli-Guivarc'h N, Clastre M: Peroxisomal localisation of the final steps of the mevalonic acid pathway in planta. Planta 2011, 234(5):903-914.

44. Thabet I, Guirimand G, Courdavault V, Papon N, Godet S, Dutilleul C, Bouzid S, Giglioli-Guivarc'h N, Clastre M, Simkin AJ: The subcellular localization of periwinkle farnesyl diphosphate synthase provides insight into the role of peroxisome in isoprenoid biosynthesis. J Plant Physiol 2011, 168(17):2110-2116.

45. Spyropoulou EA: Transcription Factors Regulating Terpene Synthases in Tomato Trichomes, PhD thesis. University of Amsterdam, Plant Physiology Department; 2012. http://dare.uva.nl/en/record/420428.

46. The GENSCAN Web Server at MIT. http://genes.mit.edu/GENSCAN.html.

47. Spyropoulou EA, Haring MA, Schuurink RC: Expression of Terpenoids 1, a glandular trichome-specific transcription factor from tomato that activates the Terpene Synthase 5 promoter. Plant Mol Biol 2014, 84(3):345-357

48. Walter MH, Hans J, Strack D: Two distantly related genes encoding 1-deoxy-d-xylulose 5-phosphate synthases: differential regulation in shoots and apocarotenoid-accumulating mycorrhizal roots. Plant J 2002 31(3):243-254

49. Paetzold H, Garms S, Bartram S, Wieczorek J, Uros-Gracia EM, Rodriguez-Concepcion M, Boland W, Strack D, Hause B, Walter MH: The isogene 1-deoxy-D-xylulose 5-phosphate synthase 2 controls isoprenoid profiles, precursor pathway allocation, and density of tomato trichomes. Mol Plant 2010, 3(5):904-916.

50. Sanchez-Hernandez C, Lopez MG, Delano-Frier JP: Reduced levels of volatile emissions in jasmonate-deficient spr2 tomato mutants favour oviposition by insect herbivores. Plant Cell Environ 2006, 29(4):546-557.

51. Okada A, Shimizu T, Okada K, Kuzuyama T, Koga J, Shibuya N, Nojiri H, Yamane $\mathrm{H}$ : Elicitor induced activation of the methylerythritol phosphate pathway toward phytoalexins biosynthesis in rice. Plant Mol Biol 2007, 65(1-2):177-187.

52. Oudin A, Mahroug S, Courdavault V, Hervouet N, Zelwer C, RodriguezConcepcion M, St-Pierre B, Burlat V: Spatial distribution and hormonal regulation of gene products from methyl erythritol phosphate and monoterpene-secoiridoid pathways in Catharanthus roseus. Plant Mol Biol 2007, 65(1-2):13-30.

53. Arimura G, Garms S, Maffei M, Bossi S, Schulze B, Leitner M, Mithofer A Boland W: Herbivore-induced terpenoid emission in Medicago truncatula: concerted action of jasmonate, ethylene and calcium signaling. Planta 2008, 227(2):453-464.

54. Kim YB, Kim SM, Kang MK, Kuzuyama T, Lee JK, Park SC, Shin SC, Kim SU: Regulation of resin acid synthesis in Pinus densiflora by differential transcription of genes encoding multiple 1-deoxy-D-xylulose 5-phosphate synthase and 1-hydroxy-2-methyl-2-(E)-butenyl 4-diphosphate reductase genes. Tree Physiol 2009, 29(5):737-749.

55. Yang Z, Park H, Lacy GH, Cramer CL: Differential activation of potato 3-hydroxy-3-methylglutaryl coenzyme A reductase genes by wounding and pathogen challenge. Plant Cell 1991, 3(4):397-405

56. Choi D, Bostock RM, Avdiushko S, Hildebrand DF: Lipid-derived signals that discriminate wound- and pathogen-responsive isoprenoid pathways in plants: methyl jasmonate and the fungal elicitor arachidonic acid induce different 3-hydroxy-3-methylglutaryl-coenzyme A reductase genes and antimicrobial isoprenoids in Solanum tuberosum L. Proc Natl Acad Sci U S A 1994, 91(6):2329-2333.

57. Ha SH, Kim JB, Hwang YS, Lee SW: Molecular characterization of three 3-hydroxy-3-methylglutaryl-CoA reductase genes including pathogeninduced $\mathrm{Hmg} 2$ from pepper (Capsicum annuum). Biochim Biophys Acta 2003, 1625(3):253-260.

58. Hui D, lqbal J, Lehmann K, Gase K, Saluz HP, Baldwin IT: Molecular interactions between the specialist herbivore Manduca sexta (lepidoptera, sphingidae) and its natural host Nicotiana attenuata: V. microarray analysis and further characterization of large-scale changes in herbivore-induced mRNAs. Plant Physio/ 2003, 131(4):1877-1893.

59. Kondo K, Uritani I, Oba K: Induction mechanism of 3-hydroxy-3-methylglutarylCoA reductase in potato tuber and sweet potato root tissues. Biosci Biotechnol Biochem 2003, 67(5):1007-1017.

60. Bede JC, Musser RO, Felton GW, Korth KL: Caterpillar herbivory and salivary enzymes decrease transcript levels of Medicago truncatula genes encoding early enzymes in terpenoid biosynthesis. Plant Mol Biol 2006, 60(4):519-531.

61. Ament K, Van Schie CC, Bouwmeester HJ, Haring MA, Schuurink RC: Induction of a leaf specific geranylgeranyl pyrophosphate synthase and emission of $(E, E)-4,8,12$-trimethyltrideca-1,3,7,11-tetraene in tomato are dependent on both jasmonic acid and salicylic acid signaling pathways. Planta 2006, 224(5):1197-1208.

62. Akhtar TA, Matsuba Y, Schauvinhold I, Yu G, Lees HA, Klein SE, Pichersky E: The tomato cis-prenyltransferase gene family. Plant J 2012, 73(4):640-652.

63. TAIR10 genome release. http://arabidopsis.org.

64. Fernandez-Calvo P, Chini A, Fernandez-Barbero G, Chico JM, Gimenez Ibanez S, Geerinck J, Eeckhout D, Schweizer F, Godoy M, Franco-Zorrilla JM, Pauwels L, Witters E, Puga MI, Paz-Ares J, Goossens A, Reymond P, De Jaeger G, Solano R: The Arabidopsis bHLH transcription factors MYC3 and MYC4 are targets of JAZ repressors and act additively with MYC2 in the activation of jasmonate responses. Plant Cell 2011, 23(2):701-715.

65. PLACE. http://www.dna.affrc.go.jp/PLACE/.

66. MEME. http://meme.sdscedu/meme/intro.html.

67. Singh KB: Transcriptional regulation in plants: the importance of combinatorial control. Plant Physiol 1998, 118(4):1111-1120.

68. Abe H, Yamaguchi-Shinozaki K, Urao T, Iwasaki T, Hosokawa D, Shinozaki K: Role of Arabidopsis MYC and MYB homologs in drought- and abscisic acid-regulated gene expression. Plant Cell 1997, 9(10):1859-1868.

69. Abe H, Urao T, Ito T, Seki M, Shinozaki K, Yamaguchi-Shinozaki K: Arabidopsis AtMYC2 (bHLH) and AtMYB2 (MYB) function as transcriptional activators in abscisic acid signaling. Plant Cell 2003, 15(1):63-78.

70. CLCbio bioinformatics software. http://www.clcbio.com/.

71. Quevillon E, Silventoinen V, Pillai S, Harte N, Mulder N, Apweiler R, Lopez R: InterProScan: protein domains identifier. Nucleic Acids Res 2005, 33(Web Server issue):W116-W120

72. Ogata H, Goto S, Fujibuchi W, Kanehisa M: Computation with the KEGG pathway database. Biosystems 1998, 47(1-2):119-128.

73. PASW Statistics 17.0. http://www.spss.com.

74. Huang S, Gao Y, Liu J, Peng X, Niu X, Fei Z, Cao S, Liu Y: Genome-wide analysis of WRKY transcription factors in Solanum lycopersicum. Mol Genet Genomics 2012, 287(6):495-513.

75. van Engelen FA, Molthoff JW, Conner AJ, Nap JP, Pereira A, Stiekema WJ: pBINPLUS: an improved plant transformation vector based on pBIN19. Transgenic Res 1995, 4(4):288-290

doi:10.1186/1471-2164-15-402

Cite this article as: Spyropoulou et al:: RNA sequencing on Solanum lycopersicum trichomes identifies transcription factors that activate terpene synthase promoters. BMC Genomics 2014 15:402.

\section{Submit your next manuscript to BioMed Central and take full advantage of:}

- Convenient online submission

- Thorough peer review

- No space constraints or color figure charges

- Immediate publication on acceptance

- Inclusion in PubMed, CAS, Scopus and Google Scholar

- Research which is freely available for redistribution 